\title{
Functional New Sphincter Ani Reconstruction by Using Neurovascualr Antropylorus Transposition After an Anorectal Excision
}

\author{
Bong Hwa Lee, Min Jung Kim, Hyoung Chul Park \\ Department of Surgery, Hallym University Sacred Heart Hospital, Hallym University College of Medicine, Anyang, Korea
}

\section{See Article on Page 7-11}

Receptors for the external sphincter response are supposed to lie in the rectal mucosa or near the mucosa. The external sphincter is only supplied by somatic pudendal nerves from the second sacral nerve. The levator ani and the pubolrectalis muscles are found to be supplied by multiple direct branches from the sacral nerves S2 to S4 [1]. If the sphincter muscle is divided at the level of the puborectaslis sling, the patient will be incontinent.

Several kinds of traumas, colorectal diseases, congenital anomalies, neurologic diseases and other miscellaneous conditions cause fecal incontinence. Anal incontinence may not be a life-threatening disease, but it is often disabling. A permanent colostomy is often preferable in cases of end-stage anal incontinence, but many patients with a stoma hope to improve their quality of life with a new functional anal sphincter and without a stoma [2].

For cases in which the anal sphincter muscles have been destroyed, several measures, such as gracilis muscle transfer, gluteus maximus transposition and an artificial sphincter, can be used for supplementing the sphincter mechanism. The main drawback of a cross-innervated skeletal muscle neosphincter is the limited range of muscle transposition because of its considerably fragile vascular pedicle. Another disadvantage is the low pressure, which is insufficient to hold stools in the neorec-

Correspondence to: Bong Hwa Lee, M.D.

Department of Surgery, Hallym University Sacred Heart Hospital, Hallym University College of Medicine, 22 Gwanpyeong-ro 170beon-gil, Dongan-gu, Anyang 431-796, Korea

Tel: +82-31-380-3772, Fax: +82-31-380-4118

E-mail: bshlee@hallym.ac.kr

(c) 2013 The Korean Society of Coloproctology

This is an open-access article distributed under the terms of the Creative Commons Attribution NonCommercial License (http://creativecommons.org/licenses/by-nc/3.0) which permits unrestricted noncommercial use, distribution, and reproduction in any medium, provided the original work is properly cited. tum, especially in the cases of gracilis muscle transfer.

Goldsmith reported eight cases of a pedicled gastric pyloric valve transposition to provide a new sphincter ani in a human being [3]. Twenty-five percent of the patients had serious complications of pelvic sepsis and transplant necrosis. Manometric studies were done preoperatively on patients with anal sphincter damage and after pyloric valve transposition. Manometric data demonstrated that six cases had tolerable anal continence. Goldsmith insisted that a vascularized pyloric valve supplied by the gastroepiploic artery within the omental pedicle could serve as a replacement for an excised anal sphincter. He also commented that the operation would have to be done by an experienced surgeon. In a real operation, when the omental pedicle is long, maintaining an effective blood supply is not easy. Schwabegger reported functional sphincter ani reconstruction using free latissimus dorsi muscle transfer with coaptation to the pudendal nerves in dogs [4]. He concluded that a free graft with nerve coaptation seemed to be superior to any pedicled muscle flap.

A cadaveric study for neoanal reconstruction showed the feasibility of pyloric valve transposition with pudendal nerve anastomosis. Anastomosis between the distal portion of the anterior branch of the vagus nerve of the pylorus and the inferior rectal nerve was also feasible. However, in my opinion, the problem of a pedicled flap can be fixed by using a free pyloric valve graft with microanastomosis of vessels and nerves. I suggest that if one is able to do a free graft of a new microvascular anastomosis between the gastroepiploic vessel of the pyloric valve and the internal pudendal vessel, the blood supply to the valve will be effectively maintained.

The pudendal nerve contains sensory, sympathetic and parasymphathetic fibers. A nerve coaptation close to the transplanted muscle allows rapid muscle reinnervation, with an estimated regeneration of $1 \mathrm{~mm}$ per day. During the intervening period, external stimulation might prevent muscle atrophy. A good portion of a well-vascularized muscular pyloric valve can be positioned as a circular physiologic contractile ring 


\section{Coloproctology Bong Hwa Lee, et al}

with optimal vascular and nerve supplies around the anal canal. However, even though a new anal sphincter would provide good continence, constipation and incomplete evacuation must continue to be considered.

In conclusion, we are not given a validated quality of life in human trial data to evaluate the true effect of anal sphincter replacement. However, we are eager to develop an easy and effective treatment to restore anal incontinence without the need for colostomy diversion.

\section{CONFLICT OF INTEREST}

No potential conflict of interest relevant to this article was reported.

\section{REFERENCES}

1. Matzel KE, Stadelmaier U, Hohenfellner M, Hohenberger W. Chronic sacral spinal nerve stimulation for fecal incontinence: long-term results with foramen and cuff electrodes. Dis Colon Rectum 2001;44:59-66.

2. Kang SB, Lee TG. Muscle regeneration: research for the treatment of fecal incontinence. J Korean Soc Coloproctol 2010;26:1-7.

3. Goldsmith HS, Chandra A. Pyloric valve transposition as substitute for a colostomy in humans: a preliminary report. Am J Surg 2011;202:409-16.

4. Schwabegger AH, Kronberger P, Obrist P, Brath E, Miko I. Functional sphincter ani externus reconstruction for treatment of fecal stress incontinence using free latissimus dorsi muscle transfer with coaptation to the pudendal nerve: preliminary experimental study in dogs. J Reconstr Microsurg 2007;23:79-85. 